\title{
Transparência interna: cumprimento e punição no processo orçamentário municipal brasileiro
}

\author{
Tássia Cruz ${ }^{1}$ \\ Gregory Michener 2 \\ Bernardo Andretti 2 \\ 1 Fundação Getulio Vargas / Escola de Políticas Públicas e Governo, Brasília / DF - Brasil \\ 2 Fundação Getulio Vargas / Escola Brasileira de Administração Pública e de Empresas, Rio de Janeiro / RJ - Brasil
}

Muito tem sido escrito a respeito da transparência externa no setor público. No entanto, a transparência interna - a divulgação inter- e intra-governamental de informações - é comumente negligenciada como objeto de estudo. Subestimar a transparência interna é surpreendente, pois ela é um fator determinante para a coordenação de políticas públicas e para uma governança democrática de qualidade. O presente artigo analisa os custos de curto e longo prazos do não cumprimento de requisitos de transparência interna vinculados aos orçamentos municipais em geral e aos gastos com educação em particular. Neste estudo, utilizamos métodos mistos, analisando quantitativamente os incentivos de curto prazo para cumprir os requisitos de transparência do financiamento da educação e, qualitativamente, as consequências futuras decorrentes do seu descumprimento. Os resultados revelam que municípios que recebem maior volume de transferências voluntárias têm maior probabilidade de atender aos requisitos de transparência interna; contudo, os custos de não cumprir tais requisitos são baixos e facilmente reversíveis a curto prazo. No longo prazo, os prefeitos que não cumprirem a regulação orçamentária, incluindo a legislação para a transparência interna, podem enfrentar consequências mais severas, como a possibilidade de serem futuramente impedidos de exercer seus cargos. No entanto, nossos resultados mostram relativamente poucos casos de punição e que, em média, essas punições só são aplicadas após dez anos de processos judiciais. De modo geral, demonstramos que os Tribunais de Contas - principais agentes para a accountability orçamentária dos 5.570 municípios brasileiros - são tão importantes quanto ineficazes para a transparência interna.

Palavras-chave: transparência pública; transferências intergovernamentais; orçamento educacional; Tribunais de Contas.

\section{Transparencia interna: cumplimiento y sanción en el proceso presupuestario municipal brasileño}

Mucho se ha escrito sobre la transparencia externa en el sector público. Sin embargo, la transparencia interna divulgación intra e intergubernamental de información- se suele pasar por alto como objeto de estudio. Subestimar la transparencia interna es sorprendente, ya que es un factor determinante para la coordinación de las políticas públicas y para una gobernabilidad democrática de calidad. Este artículo analiza los costos a corto y largo plazo del incumplimiento de los requisitos de transparencia interna, vinculados a los presupuestos municipales en general y al gasto educativo en particular. En este estudio, utilizamos métodos mixtos, analizando cuantitativamente los incentivos a corto plazo para cumplir con los requisitos de transparencia del financiamiento de la educación y, cualitativamente, las consecuencias futuras del incumplimiento. Los resultados muestran que los municipios que reciben mayores transferencias voluntarias tienen más probabilidades de cumplir con los requisitos de transparencia interna; sin embargo, los costos de incumplir dichos requisitos son bajos y fácilmente reversibles a corto plazo. A largo plazo, los alcaldes que no cumplan con la regulación presupuestaria, incluyendo la legislación de transparencia interna, podrían enfrentar consecuencias más severas, como la posibilidad de verse impedidos de ejercer sus cargos en el futuro. Sin embargo, nuestros resultados muestran relativamente pocos casos de sanción y, en promedio, estas penalidades solo se aplican después de diez años de procesos judiciales. En general, demostramos que los tribunales de cuentas, principales agentes del accountability presupuestario de los 5.570 municipios brasileños, son tan importantes como ineficaces para la transparencia interna.

Palabras clave: transparencia pública; transferencias intergubernamentales; presupuesto de educación; tribunales de cuentas. 


\section{Internal transparency: compliance and punishment in the Brazilian municipal budget process}

Much has been written about external transparency in the public sector. However, internal transparency - the inter and intragovernmental disclosure of information - is commonly overlooked as an object of study. Underestimating the importance of internal transparency is surprising, as it is a determining factor for the coordination of public policies and the quality of democratic governance. This paper analyzes the short-and-long-term costs of failing to comply with internal transparency requirements linked to municipal budgets in general and education spending in particular. In this study, we employ mixed methods, quantitatively analyzing the short-term incentives to comply with transparency requirements for education finance and, qualitatively, the future consequences of noncompliance. The results show that municipalities receiving the most voluntary transfers are more likely to meet internal transparency requirements. However, the costs of not fulfilling such requirements are low and easily reversible in the short-term. In the long-term, municipal officials who fail to comply with budget regulation, including internal transparency statutes, can face more severe consequences, such as the possibility of being barred from office. However, our results show relatively few instances of punishment, and, on average, punishments are only levied after ten years of legal processes. Overall, our results show how, as the lynchpin agents of budgetary accountability and enforcement for Brazil's 5570 municipalities, the courts of audit (Tribunais de Contas) are important but ineffective.

Keywords: public transparency; intergovernamental transfers; educational budget; Audit Courts.

\section{AGRADECIMENTOS}

O presente trabalho foi realizado com apoio da Coordenação de Aperfeiçoamento de Pessoal de Nível Superior - Brasil (CAPES) - Código de Financiamento 001.

\section{INTRODUÇÃO}

Transparência e compartilhamento de informações são fatores determinantes para a funcionalidade e adequação organizacional (Yang \& Maxwell, 2011). No entanto, a atenção do público, da academia e mesmo dos governantes tem se voltado quase exclusivamente ao campo da transparência externa, como é notável na recorrência de questões relacionadas à accountability pública e à participação social, hoje predominantes na agenda dos estudos sobre transparência (Michener, 2019). Este foco dominante tem nos feito negligenciar a importância de "transparência interna" para uma administração pública eficiente. A partilha das informações internas ao governo é pré-requisito para a accountability entre atores governamentais e a coordenação e colaboração intragovernamental, particularmente para a chamada "accountability horizontal" (Pinho \& Sacramento, 2009; Rocha, 2013). A partir desta constatação, recentes iniciativas têm surgido no Brasil, como o Decreto $n^{\circ} 10.046$ (2019), que cria obrigações e procedimentos de compartilhamento de bases de dados entre agências federais. Reconhece-se que, se o setor público de um país não é transparente entre suas unidades, não apenas a responsabilidade de cada unidade é colocada em risco, mas também a própria solidez operacional do Estado e de suas políticas (Santos \& Rover, 2019).

Este artigo investiga a transparência intragovernamental de informações financeiras no Brasil, assim como o processo de prestação de contas dos municípios. Em particular, analisamos os requerimentos legais e processos de responsabilização de curto e longo prazos existentes para "incentivar" a transparência orçamentária, olhando sobretudo para as especificidades no orçamento da educação.

\footnotetext{
${ }^{1}$ Nos referimos a transparência interna, transparência intragovernamental, e transparência indireta como sinônimos.
} 
O Brasil é um caso muito particular de federalismo, pois combina autonomia política altamente descentralizada com controle centralizado das finanças públicas (Soares \& Melo, 2016). Utilizamos a educação como objeto de análise por ser um setor em que estados e municípios são os principais responsáveis pela educação básica e, portanto, possuem significativa autonomia na gestão de suas políticas. Por outro lado, o financiamento educacional possui uma série de vinculações, além de políticas de redistribuição e de aporte intergovernamental de recursos. Nesse sentido, a educação brasileira está na encruzilhada do nosso arranjo federativo, fornecendo valiosos aprendizados sobre os desafios da transparência interna e os incentivos para cumpri-la.

Conforme estipulado pela Lei Complementar no 101 (2000) ou Lei de Responsabilidade Fiscal (LRF), e a Lei no 12.527 (2011) ou Lei de Acesso à Informação (LAI), - todos os governos locais devem enviar informações orçamentárias ao governo federal e exibir essas informações em seus websites. O preenchimento completo dos dados educacionais, por exemplo, constitui uma condição para a celebração de acordos e termos de cooperação com o Ministério da Educação ou órgãos administrativos a ele vinculados. Além disso, cada município e estado deve ter seu orçamento aprovado pelos Tribunais de Contas. Não obstante todas essas exigências, muitos entes atrasam ou sequer reportam suas informações, o que levanta graves preocupações em relação à transparência intragovernamental brasileira.

Em 2012, um sistema chamado CAUC (Sistema Auxiliar de Informações para Transferências Voluntárias) foi desenvolvido para agrupar informações dos requerimentos exigidos para a celebração das transferências voluntárias da União. Baseando-se nos dados do CAUC e nos dados de transferências realizadas através de convênios, analisamos os incentivos de "curto prazo" para o cumprimento dos requerimentos de transparência exigidos em lei. Por meio de um modelo de regressão linear com efeitos fixos, estimamos a relação entre o volume de transferências voluntárias e o não cumprimento de exigências orçamentárias. Encontramos que municípios que recebem maior quantidade de transferências voluntárias descumprem menos as exigências.

Verificamos ainda que, apesar do incentivo gerado pela condicionalidade das exigências de transparência, os "custos"2 para o seu não cumprimento são, no curto prazo, baixos. O cancelamento das transferências, em particular, é facilmente reversível e, portanto, os entes governamentais tendem a cumprir as condicionalidades somente quando estão prestes a receber esses recursos do governo federal.

A fim de verificar os "custos" de longo prazo para o não cumprimento das exigências de transparência interna, analisamos os dados das eleições municipais de 2016 e as eleições suplementares dos anos de 2017 e 2018, disponibilizados pelo Tribunal Superior Eleitoral (TSE). Tendo em vista a ameaça à reputação e a possibilidade de ter um mandato futuro cassado, esses custos (políticos) são, no longo prazo, mais severos. Argumentamos, contudo, que os Tribunais de Contas dos Estados (TCEs) $)^{3}$ têm um papel significativo de coação para o cumprimento das exigências de transparência indireta no longo prazo. As conclusões dos TCEs são enviadas às Câmaras Legislativas para aprová-las ou não. Os TCEs também podem ter um papel corretivo, quando encontram irregularidades no uso

\footnotetext{
${ }^{2}$ Nos referimos a "custos" no sentido econômico da palavra: o custo de não cumprir uma exigência legal não é só financeiro, mas refere-se ao custo de "oportunidade" (Massiani \& Picco, 2013). Assim, pretendemos analisar as implicações que são levadas em consideração na escolha dos gestores de cumprir ou não com os requerimentos - tais implicações se refletem em custos (políticos, financeiros etc.) ou benefícios para os gestores.

${ }^{3}$ Nesse artigo, iremos nos referir a Tribunais de Contas dos Estados inclusive para os Tribunais de Contas dos municípios do Rio de Janeiro e de São Paulo, e Tribunais de Contas dos municípios dos estados da Bahia, Goiás e Pará, sem diferenciá-los.
} 
dos fundos. Nesse caso, é comum que os Tribunais encaminhem o caso para o Ministério Público analisar as irregularidades.

Este estudo difere de uma análise típica de transparência externa, pois não analisamos a divulgação direta das informações orçamentárias para a população. Ao enviar os dados orçamentários para o governo federal, os municípios estão divulgando indiretamente as suas informações, uma vez que é a União que irá torná-las públicas. Assim, por se tratar de transparência interna, tal possibilidade de accountability não se refere a uma responsabilização perante a sociedade, mas perante o próprio setor público (Pinho \& Sacramento, 2009). Embora a comparação entre as duas modalidades de transparência não seja objeto deste artigo, a questão aqui analisada assume significativa importância, caso os municípios tenham maior propensão a obedecer obrigatoriedades de transparência interna em relação à externa, tendo em vista que os custos de descumpri-las podem ser maiores do que os de não divulgar informações nos portais de transparência.

Utilizamos para este estudo métodos mistos: na análise de "custos de curto prazo", estimamos quantitativamente se o valor das transferências é um fator associado ao maior cumprimento de requisitos de transparência interna; já na análise "de custos de longo prazo", utilizamos a metodologia de process tracing (Lima, 2017). Incluímos, adicionalmente, trechos de entrevistas que realizamos com dois ex-gestores do Ministério da Educação ${ }^{4}$, de modo a ilustrar o processo de transparência aqui apresentado. É importante notar que as entrevistas não se referem à metodologia utilizada para chegarmos às conclusões, representando apenas exemplificações dos nossos argumentos a partir da visão de gestores com conhecimento prático dos requerimentos orçamentários no campo da educação.

O artigo está dividido em cinco seções, incluindo esta introdução. Na segunda seção, apresentamos o contexto das transferências voluntárias no Brasil e o processo de aprovação de contas; na terceira e quarta, analisamos os custos de curto e longo prazo de não cumprir as exigências de transparência interna. Concluímos na quinta seção.

\section{CONTEXTO}

\subsection{Transferências intergovernamentais e a importância das transferências voluntárias}

A Federação brasileira se destaca pela descentralização das competências tributárias e pelo complexo sistema de transferências intergovernamentais (Prado, 2001). Conforme aponta Silva (2005), um dos principais elementos da coordenação de um sistema federalista descentralizado é a implementação de uma estrutura de transferências estável e transparente.

As transferências intergovernamentais são divididas em (i) transferências constitucionais, de tipo compulsórias, como o FPM (Fundo de Participação dos Municípios) e o Fundeb; (ii) transferências legais, reguladas por leis específicas, podendo ser estas incondicionais (sem vinculação de recursos, como os royalties de petróleo) ou condicionadas (a exemplo de repasses fundo a fundo); (iii) transferências do SUS (Sistema Único de Saúde), destinadas ao financiamento de ações e serviços do SUS; e (iv) transferências voluntárias da União, as transferências discricionárias ou negociadas (Soares \& Melo, 2016).

\footnotetext{
${ }^{4}$ Um ex-ministro da Educação (gestor 1) e um ex-presidente do Fundo Nacional de Desenvolvimento em Educação (gestor 2). A entrevista foi executada como uma conversa estruturada, realizada na mesma ocasião com os dois gestores, a quem foram feitas perguntas sobre o funcionamento do CAUC e as consequências de não cumprir os requisitos orçamentários educacionais para a transparência interna.
} 
No presente artigo, analisamos especificamente o processo de recebimento de "transferências voluntárias da União", aquelas firmadas em contratos não compulsórios entre União e governos locais. As transferências voluntárias se caracterizam por buscar viabilizar políticas setoriais. Elas permitem aos entes a ampliação de políticas públicas e de investimento (Soares \& Melo, 2016), desempenhando papel importante no incentivo do governo federal a projetos estaduais e municipais.

De acordo com o art. 25, da Lei de Responsabilidade Fiscal (LRF):

[...] entende-se por transferência voluntária a entrega de recursos correntes ou de capital a outro ente da Federação, a título de cooperação, auxílio ou assistência financeira, que não decorra de determinação constitucional, legal ou os destinados ao Sistema Único de Saúde (Lei Complementar $\left.\mathrm{n}^{\circ} 101,2000\right)$.

Segundo Baião, Cunha e Souza (2017), em 2010 as transferências voluntárias representaram 6\% das receitas totais dos municípios. De acordo com os dados de 2017 do Sistema de Informações Contábeis e Fiscais do Setor Público Brasileiro (SICONFI), as transferências da União repassadas aos municípios por meio de convênios representam em média $2,5 \%$ do total das receitas municipais. Tal proporção está um pouco acima da média de transferências recebidas pelos municípios através de convênios com os estados, correspondendo a $2,1 \%$ do total de receitas. ${ }^{5}$

Apesar do valor aparentemente baixo recebido pelos municípios por meio de transferências voluntárias, faz-se necessário considerar o grau de discricionariedade destas quando comparado a outros tipos de repasse recebidos pelos entes federados. A margem de liberdade implicada na gestão das transferências voluntárias pode significar uma importante fonte de recursos para ações estratégicas dos entes subnacionais (Bijos, 2013), contribuindo para o aumento da capacidade de gastos municipais, especialmente em períodos de recessão e baixa arrecadação em contexto de rigidez fiscal (Soares \& Melo, 2016). As transferências voluntárias já foram amplamente estudadas; há diversas evidências empíricas de que os recursos são distribuídos de maneira heterogênea pelos municípios (Brollo \& Nannicini, 2012; Meireles, 2019; Moutinho, 2016), e de que seus efeitos também podem ser diversos (Bertholini, Pereira \& Renno, 2018; Sakurai, 2013).

\subsection{Requisitos legais para transferências voluntárias da União}

Os mecanismos de transparência interna operam de modo a exigir que as prefeituras enviem suas informações orçamentárias tanto para o governo federal quanto para os Tribunais de Conta dos Estados, responsáveis por analisar as contas municipais. A verificação de requisitos que comprovem a regularidade e a saúde financeira dos entes federativos precede a celebração de transferências voluntárias da União. A legislação referente aos requisitos é diversa e intrincada. Devido a essa complexidade, em 2012 um sistema chamado CAUC foi desenvolvido com o objetivo de facilitar a prestação de contas dos entes subnacionais, os quais, a partir de um extrato emitido online, podem comprová-las perante o governo federal (Fraga, 2016). O sistema CAUC funciona com atualizações diárias (chamadas overnight), compilando informações de diversas bases de dados as quais os entes são responsáveis por preencher, como é o caso do SIOPE, referente

\footnotetext{
${ }^{5}$ Tais proporções consideram apenas os municípios que recebem alguma transferência por convênio com a União ou por convênio estadual.
} 
à educação. Atualmente, o CAUC monitora catorze requisitos de municípios e quinze de estados e do Distrito Federal. ${ }^{6}$

Um dos principais requisitos presentes no CAUC refere-se às despesas educacionais. Conforme estabelecido na Constituição Federal, art. 212, todos os estados e municípios devem aplicar, no mínimo, $25 \%$ das receitas resultantes de impostos e transferências na manutenção e desenvolvimento do ensino. Os dados para checar a conformidade quanto a este requisito são coletados pelo Fundo Nacional de Desenvolvimento em Educação (FNDE), autarquia do Ministério da Educação (MEC), e processados pelo Sistema de Informações sobre Orçamentos Públicos em Educação (SIOPE, 2019). Municípios têm até 30 de abril e estados e União até 31 de maio do período subsequente para comprovarem no SIOPE os gastos mínimos em educação. No dia posterior ao seu preenchimento, a consulta fica disponível no portal do CAUC.

Uma forma de criar incentivos para a transparência interna está estabelecida na LRF, que designa o bloqueio de transferências voluntárias do governo federal, caso os requerimentos devidos não sejam atendidos. Assim, exceção feita a recursos enviados às áreas de saúde, educação e assistência social, as transferências voluntárias aos municípios não cumpridores podem ser interrompidas (Bijos, 2013; Lei Complementar $\mathrm{n}^{\circ}$ 101, 2000). Ademais, estados e municípios inadimplentes no CAUC são legalmente impedidos de celebrar novos convênios para recebimento de transferências voluntárias. Dessa forma, o mecanismo de bloqueio das transferências voluntárias é central para a análise de custos e incentivos da transparência interna, uma vez que podem afetar diretamente a capacidade de arrecadação dos municípios.

Entretanto, apesar de a LRF estabelecer que municípios que não cumpram os requisitos compulsórios tenham suas transferências bloqueadas, esse mecanismo não é automático. Conforme demonstrado na Figura 1, além do envio das informações educacionais para o governo federal (através do preenchimento do SIOPE), os municípios devem ter suas contas aprovadas pelo Tribunal de Contas. Na prática, é comum as prefeituras enviarem dados de execução orçamentária para o TCE sem que os reportem ao governo federal. Em muitos casos, apesar de o CAUC ter atualizações diárias, o fato de um município estar negativado no sistema não se traduz em consequências legais, se as contas forem aprovadas pelo TCE. O bloqueio previsto na LRF pode ser, portanto, muitas vezes inócuo.

Observamos que o bloqueio das transferências voluntárias é efetivamente executado conforme a deliberação do TCE sobre o assunto. São Paulo e Minas Gerais são exemplos de Tribunais de Contas que interpretam as exigências de transparência interna de forma diferente do Tesouro. São Paulo, por exemplo, atualmente considera o salário dos aposentados que trabalharam na área de educação como parte dos $25 \%$ do mínimo constitucional. ${ }^{7}$ Minas Gerais, por outro lado, criou o “Termo de ajuste de gestão", no qual o Tribunal de Contas aceita que o município não cumpra com os 25\% para educação desde que firme um termo para ajustar essa irregularidade no futuro. Segundo o gestor

\footnotetext{
${ }^{6}$ Eis os requisitos: (1) Regularidade quanto a Tributos, Contribuições Previdenciárias Federais e à Dívida Ativa da União; (2) Regularidade quanto a Contribuições para o FGTS; (3) Regularidade em relação à Adimplência Financeira em Empréstimos e Financiamentos concedidos pela União; (4) Regularidade perante o Poder Público Federal; (5) Regularidade quanto à Prestação de Contas de Recursos Federais recebidos anteriormente; (6) Publicação do Relatório de Gestão Fiscal (RGF); (7) Publicação do Relatório Resumido de Execução Orçamentária (RREO); (8) Encaminhamento das Contas Anuais; (9) Encaminhamento da Matriz de Saldos Contábeis; (10) Encaminhamento de Informações para o Cadastro da Dívida Pública (CDP); (11) Exercício da Plena Competência Tributária;(12) Aplicação mínima de recursos em Educação; (13) Aplicação Mínima de Recursos em Saúde; (14) Regularidade Previdenciária; (15) Regularidade quanto à Concessão de Incentivos Fiscais (este último exclusivo aos estados).

${ }^{7}$ Em recente decisão, o STF declarou inconstitucional a norma de São Paulo sobre inclusão de gastos previdenciários nas despesas com educação (Supremo Tribunal Federal, 2020).
} 
2 ouvido neste estudo, "são 27 tribunais, cada um tem uma interpretação". O entrevistado também destacou o papel do TCE como o "único órgão que pode falar sobre as transferências voluntárias".

Em relação ao cumprimento do mínimo constitucional de $25 \%$ em educação, os municípios que não preencheram o SIOPE podem comprovar o cumprimento do mínimo constitucional através de um certificado do Tribunal de Contas. Em nossa entrevista com gestores, um entrevistado resume essa possibilidade:

[...] vamos supor que um desses itens do CAUC é a questão do cumprimento do mínimo de 25\% em educação, e o município não cumpriu. Pelo SIOPE, ele [o município] atingiu 24,99\%. Só que ele pode estar [negativado] no CAUC e conseguir a liberação de convênio, porque vale mais - acima do SIOPE e acima da análise do governo federal - o TCE, que constitucionalmente analisa as contas e tem o poder de dizer se aplicou ou não os 25\%. Então ele [o município] pode aparentemente estar [negativado] no CAUC por uma questão de não cumprir os $25 \%$, mas ele [o município] tem uma certidão do TCE ou do TCM (Gestor 1).

Se a comprovação do cumprimento do TCE é suficiente para o desbloqueio dos convênios e transferências voluntárias, isso significa que as análises e decisões dos tribunais se sobrepõem a outras instâncias (particularmente ao processo de transparência interna do governo federal determinado pela LRF). Assim, para compreender os custos de curto prazo em não cumprir as exigências de transparência interna, é imprescindível que analisemos o processo de aprovação de contas municipais pelos TCEs.

\subsection{Processo de aprovação de contas pelos TCEs}

A Constituição Federal de 1988 estabelece, no artigo 31, que o processo de aprovação de contas do Poder Executivo é de responsabilidade do Poder Legislativo, que conta com um parecer técnico anual - chamado parecer prévio - elaborado pelo Tribunal de Contas municipal, estadual, ou da União. Objetivando um controle de contas transparente e sustentável, a LRF e a LAI promovem a autonomia administrativa do TCE e o elege como principal órgão de monitoramento de contas estaduais e municipais. O TCE tem como incumbência fundamental auxiliar o Poder Legislativo no julgamento externo, gerando informações técnicas e autônomas sobre as contas do Executivo (Santana, Libonati, Vasconcelos \& Slomski, 2009).

Assim sendo, os Tribunais de Contas são órgãos providos de aparato legal e institucional com responsabilidade de promover transparência e accountability (O’Donnell, 1998; Rocha, 2013). Apesar da legislação brasileira não utilizar o termo accountability para designar o papel dos Tribunais de Contas, estes atuam no chamado "accountability horizontal" ao fiscalizar a gestão orçamentária, patrimonial e financeira dos entes sob sua jurisdição. Além disso, os TCEs possuem prerrogativa para também avaliar o reflexo da administração orçamentária e financeira no desenvolvimento econômico e social dos entes. Os tribunais são, portanto, necessários para garantir que a sociedade exerça o controle das ações e responsabilização do governo (atuando, assim, também no chamado "accountability vertical"). 8

Cada TCE é responsável por supervisionar os orçamentos municipais, posteriormente julgados pela Câmara Municipal. Os TCEs têm regras comuns entre si, mas cada um possui uma regulamentação

\footnotetext{
${ }^{8}$ Ver Pinho e Sacramento (2009) e Rocha (2013) para uma discussão sobre o termo accountability e a distinção entre os conceitos de accountability "vertical" e "horizontal".
} 
específica, com algumas peculiaridades. O cronograma de julgamento de contas municipais é emblemático dessas variações, pois se em geral segue regras parecidas, difere de forma sutil de estado para estado. O processo se inicia com as prefeituras apresentando seus balancetes, trazendo informações sobre contas anuais de administração financeira. Alguns estados impõem o prazo de entrega desses balancetes para o dia 31 de março do próximo exercício financeiro (é o caso de São Paulo, Paraná e Paraíba), enquanto outros impõem o prazo de 180 dias após o fim do exercício financeiro (como o estado do Rio de Janeiro).

Os tribunais, então, elaboram o parecer prévio para apreciação dos vereadores, que votam pela aprovação ou rejeição das contas na Câmara Municipal (Lopes, Pederneiras \& Silva, 2009). O parecer também segue um cronograma que varia entre estados. A maioria tem até o último dia do ano seguinte do recebimento das contas para emitir o parecer prévio (por exemplo, São Paulo e Rio de Janeiro), enquanto outros têm prazo de um ano após o recebimento das contas (por exemplo, Paraná e Minas Gerais).

É importante notar, contudo, que quem de fato aprova ou não as contas é o Poder Legislativo (as Câmaras Municipais). Mas o parecer produzido pelo TCE que vai à votação na Câmara Municipal só deixa de prevalecer caso ao menos dois terços dos membros do Legislativo votem contra ele, com motivações claras contra o parecer (Andrada \& Barros, 2010). A comissão técnica das Câmaras também é responsável por preparar pareceres sobre as contas municipais, complementando a análise dos TCEs. Apesar de haver exceções (como foi o caso do Rio de Janeiro, que aprovou as contas de 2016 com parecer contrário do TCE) ${ }^{9}$, em geral a análise dos Tribunais de Contas é aprovada pelo Legislativo. Corrobora para tal conjuntura o fato de os conselheiros dos TCEs serem, muitas vezes, ex-parlamentares (Speck, 2011). Após a deliberação na Câmara, um Decreto Legislativo de aprovação ou rejeição das contas é publicado.

O período de julgamento também varia entre os estados brasileiros. Após esse processo de apuração das contas pelos tribunais, alguns estados fixam data para a eventual aprovação ou rejeição pelos vereadores. Em Minas Gerais, por exemplo, determina-se que, em não havendo manifestação da Câmara Municipal em 120 dias contados do recebimento do parecer prévio, o processo é encaminhado para o Ministério Público.

Se as contas forem finalmente aprovadas pela Câmara, o município tem respaldo legal para continuar recebendo as transferências voluntárias e realizar novos convênios, mesmo quando não está cumprindo os requisitos de transparência interna. Conclui-se, portanto, que é a interpretação do Tribunal de Contas a que de fato pesa, potencialmente desestimulando as prefeituras a respeitar os demais mecanismos de transparência intergovernamental. Essa conjuntura, na qual TCEs coexistem com outros dispositivos de transparência interna, termina por enfraquecer os últimos, tendo em vista a possibilidade de decisões dos tribunais prevalecerem sobre entendimentos contrários.

Existe, adicionalmente, a possibilidade de judicialização das decisões, regularizando casos que aparecem como irregulares no CAUC. Os governos dos estados de Minas Gerais e Acre, por exemplo, foram bloqueados pelo CAUC por irregularidades referentes às exigências de educação, mas conseguiram liberação por ação judicial no Supremo Tribunal Federal. ${ }^{10}$ Com a judicialização das decisões, o judiciário muitas vezes reconhece a irregularidade no SIOPE, mas julga que tal irregularidade não tem validade.

\footnotetext{
${ }^{9}$ Ver Graça (2016) para uma análise da relação entre o Executivo e o Legislativo no estado do Rio de Janeiro.

${ }^{10}$ Tutela Provisória na Ação Cível Originária 3.111 de Minas Gerais e Medida Cautelar na Ação Cível Originária 3.104 do Acre.
} 
RAP | Transparência interna: cumprimento e punição no processo orçamentário municipal brasileiro

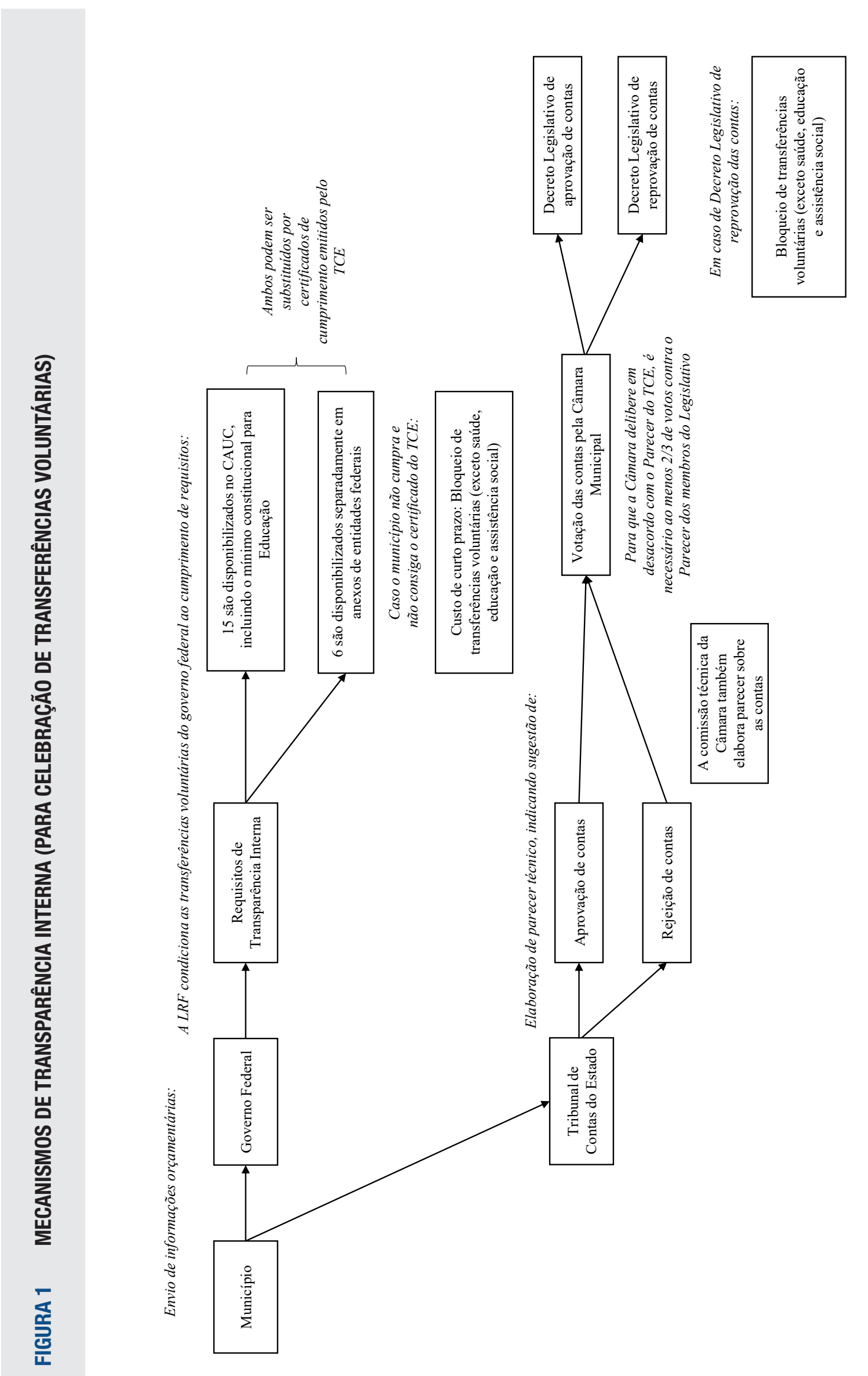

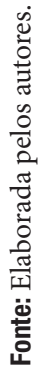

REVISTA DE AdMINIStRAÇão PÚBLICA ｜ Rio de Janeiro 55(2): 357-377, mar. - abr. 2021 


\section{CUSTOS E INCENTIVOS DE CURTO PRAZO}

Inicialmente, analisamos os custos de curto prazo em desobedecer às exigências orçamentárias em educação. Uma vez que as transferências voluntárias recebidas pelos municípios podem ser bloqueadas por descumprirem a LRF, verificamos se tal penalização de fato ocorre. Consideramos, portanto, o eventual bloqueio um custo financeiro de curto prazo para os municípios.

Existem ainda outros mecanismos que poderiam gerar custos de curto prazo pelo não cumprimento dos requisitos de transparência interna no setor educacional, a exemplo da Portaria/ MEC no 844 (2008), do Ministério da Educação. Essa Portaria determina que o não preenchimento do SIOPE deveria impedir o ente federado de celebrar novos convênios ou termos de compromisso com o MEC. Entretanto, devido ao fato de tal impedimento não poder ser estabelecido por uma Portaria, municípios têm a prerrogativa de entrar com ação judicial contra ela. Segundo os gestores entrevistados, essa Portaria serve tão somente para "assustar" os gestores públicos, não tendo efeito prático sobre as transferências voluntárias. Por essa razão, não iremos analisá-la como um custo de curto prazo.

\subsection{Dados}

Para a análise dos custos de curto prazo, utilizamos duas fontes de dados: (I) CAUC e (II) SICONV. Os dados do CAUC são organizados pela Secretaria do Tesouro Nacional (STN) e informam sobre o cumprimento das exigências para o recebimento de transferências voluntárias. Obtivemos as informações de todos os relatórios do CAUC referentes a 5 de abril de 2018, através de solicitação pelo Sistema Eletrônico de Serviço de Informação ao Cidadão (e-SIC). ${ }^{11}$ Tais relatórios compilam os extratos do CAUC para todos os entes municipais brasileiros, informando a data de cumprimento de cada requerimento, ou se ainda falta a sua comprovação. Dos 5.570 municípios brasileiros, 4.816 municípios $(86,46 \%$ do total) não cumpriam pelo menos um dos 14 requisitos apresentados pelo CAUC.

Dois dos requisitos listados pelo CAUC são objeto da nossa análise: os itens 3.2 (Encaminhamento do Relatório Resumido de Execução Orçamentária - RREO) e 4.2 (Aplicação Mínima de Recursos em Educação), por representarem transparência e cumprimento com as exigências educacionais, respectivamente. As informações de encaminhamento do RREO vêm do STN/SICONFI, enquanto a fonte dos dados de aplicação mínima é o SIOPE/FNDE. Apesar das informações do SIOPE servirem para alimentar o Anexo 8 do RREO, é possível que um município tenha enviado o RREO sem ter preenchido o SIOPE, e vice-versa.

Segundo a LRF Art. 52, o Poder Executivo dos entes da Federação deve publicar as informações do RREO até 30 dias após o encerramento de cada bimestre. Analisamos os relatórios entregues até o dia 5 de abril de 2018. Nesta data, os municípios deveriam ter entregado o RREO do primeiro bimestre de 2018, sendo o fim de março a data-limite. Dos 5.570 municípios brasileiros, 63,78\% não haviam comprovado a entrega do RREO. Apenas 2.017 municípios (36,22\% do total) haviam encaminhado o relatório resumido com validade para 30 de maio de 2018 (prazo de envio do relatório do $2^{\circ}$ bimestre). É importante notar que o sistema se mantém aberto para envio após a data-limite.

\footnotetext{
${ }^{11}$ Solicitamos o "Relatório de Situação de Vários Entes", em particular do “CNPJ principal do Ente Federado".
} 
Os itens do CAUC que envolvem vinculação constitucional - particularmente as aplicações mínimas de educação e saúde - são mais difíceis de serem revertidos. Esperaríamos, portanto, uma maior propensão ao seu cumprimento, a fim de evitar o bloqueio de transferências voluntárias. Como o CAUC é atualizado diariamente, espera-se que itens cujo descumprimento é facilmente revertido no sistema, como é o caso da entrega do RREO, sirvam menos para incentivar o cumprimento dos municípios do que aqueles de difícil reversão.

De fato, verificamos que o atendimento ao segundo requisito analisado - a aplicação mínima em educação - é significativamente maior que o de outros itens de transparência interna, corroborando a hipótese de que esta é uma obrigação considerada de maior relevância. Em 5 de abril de 2018, 82,96\% dos municípios cumpriam com a aplicação mínima em educação (válida até 30 de janeiro de 2019); os demais 17,04\% não haviam comprovado este item até o momento analisado. A maior parte dos 949 municípios que não confirmaram o mínimo constitucional também não havia entregado o RREO (776 não obedeceram aos dois requisitos). A proporção de prefeituras a cumprir a aplicação mínima, no entanto, deve aumentar ao longo do ano, conforme enviem o RREO.

A segunda base de dados utilizada para a análise dos custos de curto prazo da transparência interna é o SICONV. Publicadas pelo Ministério da Economia (anteriormente sob o Ministério do Planejamento, Desenvolvimento e Gestão), ${ }^{12}$ as informações do SICONV se referem a convênios, acordos e valores ligados às transferências voluntárias.

\subsection{Transparência interna e transferências voluntárias}

A fim de compreender se o bloqueio das transferências voluntárias é, de fato, um custo de curto prazo para o não cumprimento dos requerimentos de transparência interna, juntamos as informações de atendimento aos requisitos apresentados no CAUC com os dados de convênios do SICONV.

Antes de avaliar a relação entre o cumprimento das exigências de transparência interna e os valores recebidos por convênios, cabe ressaltar a dificuldade de se bloquear uma transferência em andamento, devido à necessidade de respeitar a continuidade da administração pública. Bloquear a realização de um convênio é diferente de bloquear desembolsos oriundos de convênios previamente firmados. Isto é, um município que eventualmente descumpra requerimentos do CAUC pode continuar recebendo repasses de convênios acordados no passado. Segundo entrevista com gestores:

[...] Não se pode impedir a continuidade de uma ação. Então, se o município já recebeu $40 \%$ do recurso, a obra da execução, [o governo federal] vai travar aquele convênio de desembolso do restante da obra porque o 'cara' [município] entrou no CAUC? Não tem sentido (Gestor 1).

De fato, apesar de 63,78\% dos municípios não terem entregue o RREO em abril de 2018, apenas uma pequena proporção de convênios foi cancelada neste ano. Observando o histórico dos convênios assinados desde meados de setembro de 2008 até a data analisada, verifica-se que 3,3\% dos convênios foram cancelados e $8,87 \%$ foram anulados. Desses convênios que foram cancelados ou anulados na última década, menos de $1 \%$ voltam a ser executados ( $99,87 \%$ se mantiveram anulados).

${ }^{12}$ Recuperado de http://portal.convenios.gov.br/download-de-dados 
Apresentamos na Figura 2 os 8,87\% de convênios que foram anulados, distribuídos ao longo dos últimos 10 anos. De todos os convênios anulados desde setembro de 2008, apenas $11,7 \%$ das anulações ocorreram em 2018, confirmando que entre os 63,78\% municípios que não entregaram o RREO, poucos tiveram o convênio anulado. Constata-se, portanto, que o custo de não cumprir essa exigência de transparência não é o de anular um convênio já existente. Ou seja, uma vez firmado o convênio, desobedecer aos requisitos da LRF deixa de ser um custo para o recebimento das transferências.

\section{FIGURA 2 HISTÓRICO DE CONVÊNIOS}
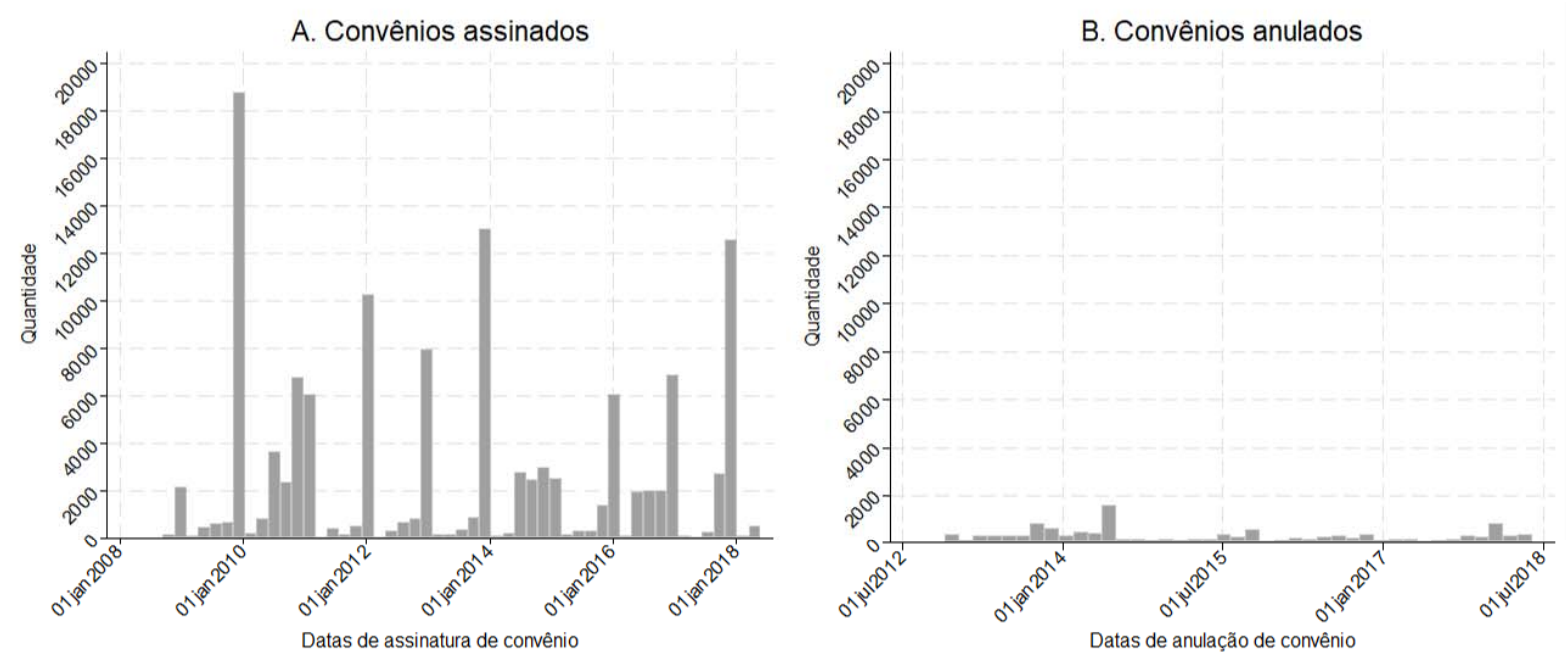

Fonte: Elaborada pelos autores baseado em dados do SICONV (maio/2018).

Ainda assim, provavelmente a variável que mais interessa aos entes federados é o valor dos recursos transferidos, em vez de a quantidade de convênios assinados. Isto é, mesmo que a anulação de convênios já existentes não represente um custo real para os municípios, o valor das transferências voluntárias de convênios passados pode servir de incentivo para o cumprimento dos requerimentos de transparência interna (com o objetivo de estabelecer convênios futuros). Para verificar se o valor dos repasses está negativamente relacionado com o cumprimento das exigências da LRF, estimamos a relação entre o montante de transferências voluntárias recebido pelos municípios e se o município cumpriu ou não com requisitos do CAUC. Formalmente, estimamos uma regressão linear do log (ln) do valor das transferências voluntárias recebidas de convênios estabelecidos anteriormente (até 2017) e o cumprimento de requerimentos em 2018, conforme apresentado na equação (1) a seguir. ${ }^{13}$

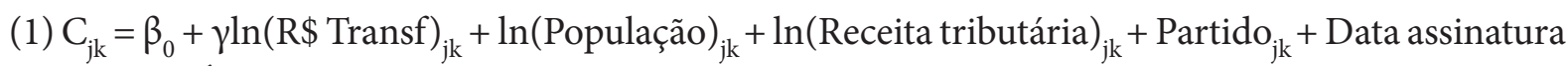
contrato $_{j \mathrm{k}}+$ Órgão Adm Pública $_{\mathrm{jk}}+$ Natureza jurídica $_{\mathrm{jk}}+\mathrm{EF} \mathrm{Estado}_{\mathrm{k}}+\varepsilon_{\mathrm{j}}$

\footnotetext{
${ }^{13}$ Como as proporções das variáveis de resultado não estão nas caudas da distribuição, a regressão linear é preferível ao modelo logístico para esta análise (Hellevik, 2009).
} 
Na equação (1), $C_{j k}$ é um resultado binário que assume o valor um se o município não cumprir os requerimentos e zero caso contrário. Testamos três resultados de não conformidade: (i) "O município não cumpre pelo menos um requisito do CAUC", (ii) "O município não comprova o envio do RREO" e (iii) "O município não cumpre com o mínimo constitucional em educação". A variável independente (ln Transferências, em $\mathrm{R} \$$ ) é o logaritmo natural das transferências voluntárias do governo federal para cada município $j$ no estado $k$. Restringimos nossa análise para convênios que foram estabelecidos previamente, ou seja, entre 2008 e 2017, para todas as áreas da administração pública exceto educação, saúde e assistência social (as quais não são canceladas em caso de descumprimento com os requerimentos de transparência interna).

Tendo em vista que o objetivo em estimar a equação (1) é o de verificar se maiores montantes de recursos transferidos através de transferências voluntárias estão relacionados ao maior cumprimento com os requisitos do CAUC, é necessário controlarmos estatisticamente para variáveis que endogenamente podem afetar tanto os valores das transferências quanto o cumprimento dos requisitos. Incluímos na nossa estimação variáveis de controle para população, receita tributária do município, filiação partidária do prefeito, média de dias desde as datas de assinatura dos contratos por município e o período da análise, órgão superior do concedente (isto é, a que Ministério ou Área da Administração Pública o convênio está associado), ${ }^{14}$ e natureza jurídica do proponente (se Administração Pública Municipal ou outros $\left.{ }^{15}\right)$. Incluímos, adicionalmente, efeitos fixos de estado $(k)$ para considerar diferenças referentes a características regionais.

Se municípios com maior população recebem maiores transferências por convênios e, ao mesmo tempo, possuem maior propensão a cumprir os requisitos do CAUC, seja por receberem maior atenção do governo federal, por exemplo, o tamanho da população pode enviesar os resultados encontrados. Similarmente, o partido do prefeito pode estar relacionado com a propensão de cumprir os requisitos do CAUC, e também ao montante de recursos recebidos por transferências voluntárias. Diversos autores argumentam que alinhamento político é um fator crucial para o volume de recursos recebidos por transferências intergovernamentais (Bracco, Lockwood, Porcelli \& Redoano, 2015; Brollo \&Nannicini, 2012; Feld \& Schaltegger, 2005; Veiga \& Pinho, 2007). Por outro lado, especificamente na área da educação, Cruz e Silva (2020) não encontram nenhuma relação estatisticamente significativa entre o alinhamento do prefeito com o presidente e a quantidade de recursos recebidos por meio das transferências intergovernamentais do FNDE/Ministério da Educação. De toda forma, a inclusão do partido do prefeito na nossa estimação nos permite evitar vieses provenientes dos efeitos de preferências do partido quanto ao cumprimento dos requisitos do CAUC e os montantes recebidos pelas transferências de convênios.

\footnotetext{
${ }^{14}$ Incluímos três variáveis como controle do órgão concedente, as quais se referem à proporção de convênios no município que são: do Ministério do Esporte, do Ministério do Turismo e do Ministério da Agricultura, Pecuária e Abastecimento. A escolha desses três órgãos se deu porque estes representam os Ministérios com maior proporção de convênios realizados.

15 ‘Outros’ inclui Administração Pública Estadual, Consórcio Público, Empresa pública / Sociedade de economia mista e Organização da Sociedade Civil.
} 


\section{TABELA 1 CAUC \& CONVÊNIOS}

\begin{tabular}{|c|c|c|c|}
\hline & $\begin{array}{l}\text { Não cumpre pelo menos } 1 \\
\text { requisito }\end{array}$ & $\begin{array}{c}\text { Não comprovação de envio } \\
\text { do RREO }\end{array}$ & $\begin{array}{l}\text { Não cumpre com o mínimo } \\
\text { constitucional em educação }\end{array}$ \\
\hline & [1] & [2] & [3] \\
\hline \multirow[t]{2}{*}{ In(R\$ Transferência $)_{j k}$} & $-0,030$ & $-0,025$ & $-0,030$ \\
\hline & {$[0,007]^{\star \star \star}$} & {$[0,007]^{\star \star \star}$} & {$[0,006]^{\star \star \star}$} \\
\hline \multirow[t]{2}{*}{$\ln (\text { População) })_{j k}$} & 0,012 & $-0,012$ & 0,022 \\
\hline & {$[0,007]^{*}$} & {$[0,007]^{*}$} & {$[0,007]^{\star \star \star}$} \\
\hline \multirow[t]{2}{*}{ In(R\$ Receita tributária $)_{\mathrm{jk}}$} & $-0,031$ & $-0,029$ & 0,028 \\
\hline & {$[0,008]^{\star \star \star}$} & {$[0,009]^{\star \star \star}$} & {$[0,009]^{\star \star \star}$} \\
\hline Partido $_{\mathrm{jk}}$ & $\operatorname{Sim}$ & Sim & Sim \\
\hline Data assinatura contrato $_{\mathrm{jk}}$ & $\operatorname{Sim}$ & $\operatorname{Sim}$ & $\operatorname{Sim}$ \\
\hline Órgão Adm Pública ${ }_{\mathrm{jk}}$ & Sim & $\operatorname{Sim}$ & $\operatorname{Sim}$ \\
\hline Natureza jurídica $_{\mathrm{jk}}$ & $\operatorname{Sim}$ & Sim & Sim \\
\hline Efeito Fixo estado ${ }_{k}$ & $\operatorname{Sim}$ & Sim & Sim \\
\hline$N$ & 5.114 & 5.114 & 5.114 \\
\hline $\mathrm{R}^{2}$ & 0,13 & 0,26 & 0,07 \\
\hline
\end{tabular}

${ }^{*} p<0,1 ;{ }^{* *} p<0,05 ;{ }^{* *} p<0,01$

Erros-padrão robustos.

Fontes: CAUC/STN (abril/2018), Siconv (maio/2018), SIOPE/FNDE e TSE. R\$ Transferência se refere ao valor das transferências voluntárias realizadas através de convênios existentes (exceto para educação, saúde e assistência social) estabelecidos até 2017. R\$ Receita tributária se refere à receita tributária per capita.

Conforme apresentado na Tabela 1, existe uma correlação negativa entre o valor recebido de transferências voluntárias de convênios de anos anteriores e o cumprimento de pelo menos um dos requisitos do CAUC em 2018 (coluna [1]). Particularmente, para um aumento de 1\% do valor das transferências, verificamos que a probabilidade da não conformidade com um dos requisitos do CAUC reduz em três pontos percentuais, mantendo todas as outras variáveis constantes. Os resultados da coluna [2] também mostram que, quanto maiores as transferências recebidas, menor a probabilidade de não comprovar o relatório de transparência orçamentária. Segundo a coluna [2], a probabilidade de não entregar o relatório é de -2,5 pontos percentuais por unidade de mudança no log das transferências. A coluna [3] apresenta que aumentos nas transferências voluntárias também levam a um menor descumprimento do mínimo constitucional (de -3 pontos percentuais).

É importante notar que, ao restringirmos as transferências de convênios realizados em anos anteriores, não estamos analisando a relação imediata entre as transferências e o cumprimento dos requisitos. Os maiores volumes de transferência voluntária não se devem ao cumprimento dos requerimentos (o que significaria uma relação inversa entre a variável dependente e a independente), justamente porque as transferências referem-se a convênios já estabelecidos (os quais, como discutido anteriormente, não são cancelados por não cumprimento de requisitos de transparência interna). 
Ou seja, o cumprimento dos requerimentos da LRF pode melhorar a relação do ente federado com o governo federal, acarretando aumentos das transferências recebidas no futuro, mas não passadas.

Observamos, de fato, que quanto maiores as transferências passadas, maior o incentivo para o cumprimento futuro. São duas as possíveis razões para os resultados encontrados. Primeiro, o valor das transferências pode aumentar o custo do descumprimento. Se o volume de recursos recebidos por transferências voluntárias é alto, o custo de atraso e eventual não recebimento dessas transferências aumenta.

A segunda razão para os valores das transferências voluntárias possuírem uma relação negativa com o descumprimento dos requerimentos de transparência é que esta é uma relação "endógena" referindo-se às características dos gestores. Semelhante a outros estudos na área (particularmente Soares \& Melo (2016)), utilizamos como proxy para capacidade técnica do gestor a receita tributária per capita do município em 2018. Entretanto, ainda é possível que gestores mais proativos em levar projetos com recursos federais para seus municípios também sejam gestores que possuem maior preocupação com o cumprimento da lei. Essa (possível) endogeneidade informa sobre a importância dos gestores em relação ao cumprimento dos requisitos de transparência interna. $\mathrm{Ou}$ seja, a endogeneidade indicaria que gestores "mais efetivos" valorizam a transparência interna, o que é um resultado relevante por si só.

\section{CUSTOS E INCENTIVOS DE LONGO PRAZO}

Para investigar os custos de longo prazo para o não cumprimento das exigências de transparência interna, ou - similarmente - os incentivos para o seu cumprimento, utilizamos o process tracing como metodologia de análise das consequências futuras ocorridas em decorrência do cumprimento das exigências de transparência. O método de process tracing se refere ao mapeamento sistemático de evidências analisadas à luz de hipóteses pré-definidas (Bennett \& Checkel, 2014; Lima, 2017).

Trabalhamos com a hipótese de que os custos de não cumprir as exigências legais são mais significativos no longo prazo do que no curto prazo, tendo em vista fatores que têm consequências relevantes para gestores e, portanto, os levaria a cumprir os requisitos. Para explorar tal hipótese, é necessário identificarmos as consequências que de fato ocorrem no longo prazo, as quais qualificamos como "custos políticos" de não cumprimento. Sendo estes custos particularmente altos, supõe-se que eles terão maior influência nas decisões dos gestores. Analisamos, então, quanto tempo leva para que tais "custos" sejam efetivados - ou seja, para que o não cumprimento gere consequências reais para os gestores.

\subsection{Dados do Tribunal Superior Eleitoral (TSE)}

A partir do cruzamento de duas bases de dados disponibilizadas publicamente pelo TSE, analisamos as informações das eleições municipais de 2016 e das eleições suplementares de 2017 e 2018. A primeira base foi construída a partir da consulta de todos os candidatos a prefeito em 2016 e do motivo de cassação de cada candidatura. Nas eleições de 2016, 458 candidatos a prefeito dos 5.570 municípios brasileiros tiveram suas candidaturas indeferidas, enquanto oito tiveram suas candidaturas cassadas.

Verificamos, especificamente, casos em que as candidaturas foram impedidas por motivos de rejeição de contas públicas. Conforme a Lei Complementar nº 64/1990 (1990, grifo nosso), são considerados inelegíveis: 
[...] os que tiverem suas contas relativas ao exercício de cargos ou funções públicas rejeitadas por irregularidade insanável que configure ato doloso de improbidade administrativa, e por decisão irrecorrível do órgão competente, salvo se esta houver sido suspensa ou anulada pelo Poder Judiciário, para as eleições que se realizarem nos 8 (oito) anos seguintes [...]

Redação dada pela Lei Complementar no 135, de 2010 (denominada de Lei da "Ficha Limpa").

A segunda base de dados foi construída a partir da consulta de todas as eleições suplementares que ocorreram em 2017 e 2018. Para isso, fez-se a coleta de cada município em que houve eleições suplementares no site do TSE. Com o objetivo de analisar o motivo da ocorrência de novas eleições, foram coletadas informações sobre o motivo da cassação dos prefeitos a partir dos processos de cada Tribunal Regional Eleitoral (TRE) correspondente, assim como os processos do TSE. A busca se deu em grande medida pelo portal de "Pesquisa Simultânea de Jurisprudência dos Tribunais Eleitorais", no qual buscou-se pela palavra-chave "indeferimento" e pelo nome do município. Quando essa busca não foi suficiente, a pesquisa se deu pela consulta do número dos processos dos tribunais, disponibilizado em cada resolução que fixa novas eleições para os municípios correspondentes.

Com isso, foi possível aferir o motivo da cassação das 106 eleições suplementares previstas no período. Importante notar que, dessas, cinco foram suspensas pois os prefeitos conseguiram liminares para voltar ao exercício do cargo. A amostra final, portanto, consistiu de 101 casos de eleições suplementares. Apesar dessas proporções serem pequenas em relação ao total de municípios brasileiros, elas indicam potencialmente um alto custo político de não cumprimento com os requerimentos orçamentários. A punição de poucos gestores pode ter um efeito de aprendizado em todos os demais.

\subsection{Análise dos dados do TSE}

A partir da primeira base, de eleições municipais de 2016, 13 casos foram identificados como irregulares ou por citarem expressamente o artigo supracitado da Lei Complementar $n^{\circ} 64$, referente à rejeição de contas, ou por apontarem "contas reprovadas" como motivo do impedimento. Todos os treze candidatos a prefeito tiveram suas candidaturas indeferidas. Ademais, 203 casos foram enquadrados pela Lei da "Ficha Limpa", cujas candidaturas também foram indeferidas. Nesses casos, não foi possível especificar o motivo exato do indeferimento da candidatura.

A segunda base de dados, de eleições suplementares de 2017 e 2018, permitiu obter resultados mais precisos, visto que cada motivo de cassação foi analisado individualmente. Das 101 eleições suplementares ocorridas, 24 tiveram como motivo a rejeição de contas públicas dos prefeitos eleitos em 2016 (Tabela 2). A partir da Tabela 2, identifica-se um custo político de longo prazo associado ao não cumprimento das exigências referentes às contas públicas. Sabe-se que há uma defasagem entre o tempo do envio das contas para aprovação e a efetiva análise, visto que o processo de aprovação ou rejeição de contas é analisado pelo Tribunal de Contas Estadual (TCE) e, depois, votado na Câmara Municipal, pelos vereadores, conforme descrito na seção 2.2. A média do ano de rejeição de contas para os 24 casos identificados é 2007. Isso significa que o processo de julgamento de contas demorou, em média, uma década para se materializar e gerar consequências diretas para os incumbentes. 
RAP | Transparência interna: cumprimento e punição no processo orçamentário municipal brasileiro

\section{TABELA 2 PREFEITOS ELEITOS NAS ELEIÇÕES MUNICIPAIS DE 2016, CASSADOS POR REJEIÇÃO DE CONTAS PÚBLICAS}

\begin{tabular}{lcc}
\hline Estado & Município & Ano de Rejeição \\
\hline AM & Novo Aripuanã & 2011 \\
ES & Fundão & 2011 \\
ES & Muqui & 2008 \\
MG & Ibiracatu & 2003 e 2004 \\
MG & Santana da Vargem & 2005 \\
MG & Campo Florido & 2003 e 2004 \\
MG & Santa Rita de Minas & 2007 e 2008 \\
MG & Cristiano Otoni & 2012 \\
MG & Guaraciama & 2001 \\
MG & Ervália & 2011 \\
MG & Santa Cruz de Salinas & 2015 \\
PR & Nova Laranjeiras & 2011 \\
RS & Butiá & $2009,2010,2011$ \\
RS & Salto do Jacaí & 2007 \\
SP & Sebastianópolis do Sul & 2011 \\
SP & Mombuca & 2012 \\
SP & Mairinque & 1992 \\
SP & Itatinga & 2011 e 2012 \\
SP & Rincão & 2012 \\
T0 & Taguatinga & 2009 e 2010 \\
MA & Bacabal & 1997 a $2004^{*}$ \\
MG & São Bento Abade & 2001 a $2004^{\star}$ \\
MG & Campo Azul & 2009 a 2012* $/ 2009$ a 2012* \\
RS & São Vicente do Sul & 2009 a 2012*/2009 a 2012* \\
\hline & &
\end{tabular}

*Casos em que o TRE/TSE não especificou o ano de rejeição de contas. Nesses casos, colocou-se o período de exercício equivalente.

Fonte: Elaborada pelos autores baseado em TSE.

Ademais, aponta-se para a possibilidade de assimetrias regionais no processo de prestação de contas. Quinze (62,5\%) dos 24 casos ocorreram nos estados de Minas Gerais e São Paulo, emergindo a possibilidade de que esses tribunais são mais eficientes no julgamento de contas que outros. Ao mesmo tempo, o grande número de municípios nesses estados implica que haja maior incidência de reprovação de contas (são 853 cidades em Minas Gerais e 645 em São Paulo, o que representa aproximadamente $27 \%$ do total das cidades brasileiras). O presente estudo não foi capaz de estabelecer relações causais sobre o tópico, sendo este um tema relevante para pesquisas futuras.

Tendo em vista nosso objetivo de apontar para casos de associação entre rejeições de contas públicas e custos de longo prazo a nível individual (prefeitos), podemos concluir, a partir dos presentes dados, 
que há a possibilidade da cassação do mandato por motivos de rejeição de contas passadas. Porém, demonstrou-se que tal defasagem é muito longa e que, potencialmente, o processo não funciona da mesma forma para todos os estados.

\section{CONCLUSÃO}

Orçamentos transparentes podem levar a melhorias na qualidade de políticas públicas de diversas maneiras, como, por exemplo, reduzindo a corrupção na transferência de recursos, melhorando a eficiência nos gastos e gerando estímulos para políticas de melhor qualidade (De Renzio, Wehner \& Wehner, 2017). No entanto, governos podem decidir ocultar informações orçamentárias quando os custos (tanto políticos quanto monetários) de não divulga-las não sejam altos o suficiente para incentivar a transparência (Michener, Contreras \& Niskier, 2018). Esse parece ser o caso brasileiro, em detrimento de despesas públicas essenciais como a educação.

No presente artigo, buscou-se analisar os custos da falta de transparência interna (não reportar dados orçamentários a nível municipal), bem como os custos de não respeitar as obrigações orçamentárias, a exemplo do não cumprimento do mínimo de despesas em educação. Como foi possível notar, existem custos financeiros e políticos (incluindo custos de reputação) de curto e longo prazo em não atender aos requisitos orçamentários. Contudo, eles são fracos - e podem ser revertidos tanto pelos Tribunais de Contas quanto judicialmente.

Os mecanismos de curto prazo analisados pelo artigo se referem às transferências voluntárias e à possibilidade de atraso ou bloqueio delas. A partir de dados do CAUC e do SICONV, foi possível aferir que boa parte dos municípios se encontra inadimplente com pelo menos um dos itens obrigatórios para o recebimento de transferências voluntárias: 86,48\% das prefeituras não cumpriam pelo menos um dos 14 requisitos expostos no CAUC, 63,78\% não haviam comprovado o envio do RREO, e 17,04\% não comprovaram o mínimo em despesas educacionais.

Já no longo prazo, os custos de não cumprimento são mais severos. Contudo, tais consequências ocorreram, em média, após dez anos do planejamento do orçamento. Em outras palavras, um prefeito infrator pode gozar de dois mandatos consecutivos ( 8 anos de mandato), mesmo que as infrações do primeiro mandato deveriam tê-lo impedido de ser reeleito. Tendo em vista a incerteza sobre a punição e o tempo de tramitação para tais consequências, não é claro se os custos de não cumprimento de longo prazo são capazes de influenciar positivamente as escolhas de transparência interna dos gestores públicos.

Por fim, este artigo ressalta a importância dos Tribunais de Contas e sua influência sobre a celebração de convênios e o recebimento de transferências voluntárias. Verificamos que a interpretação dos TCEs é a que de fato conta para o gestor, potencialmente desincentivando os municípios a reportarem suas informações ao Tesouro Nacional. Tal conclusão implica que a concorrência de procedimentos de coleta de informações e fiscalização das decisões orçamentárias enfraquece a atuação do governo federal na garantia de transparência interna, tendo em vista que as decisões dos TCEs podem se sobrepor a decisões contrárias. Sendo assim, discutir a atuação dos TCEs é de suma importância também para os mecanismos de transparência interna e accountability dos atores governamentais brasileiros. 


\section{REFERÊNCIAS}

Andrada, A. C., \& Barros, L. C. (2010). O parecer prévio como instrumento de transparência, controle social e fortalecimento da cidadania. Revista do tribunal de contas do estado de Minas Gerais, 77(4), 53-75.

Baião, A. L., Cunha, A. S. M., \& Souza, F. S. R. N. (2017). Papel das transferências intergovernamentais na equalização fiscal dos municípios brasileiros. Revista do Serviço Público, 68(3), 583-610. Recuperado de https://doi.org/10.21874/rsp. v68i3.1406

Bennett, A., \& Checkel, J. (Orgs.). (2014). Process Tracing: From Metaphor to Analytic Tool. Cambridge, UK: Cambridge University Press. Recuperado de https://doi.org/10.1017/CBO9781139858472

Bertholini, F., Pereira, C., \& Renno, L. (2018). Pork is policy: Dissipative inclusion at the local level. Governance, 31(4), 701-720. Recuperado de https:// doi.org/10.1111/gove.12331

Bijos, D. (2013). Federalismo, instituições políticas e relações intergovernamentais: um estudo sobre os elementos determinantes das transferências voluntárias da União para os municípios do estado de Minas Gerais (Dissertação de Mestrado). Universidade de Brasília, Brasília, DF. Recuperado de http://repositorio.unb.br/handle/10482/13434

Bracco, E., Lockwood, B., Porcelli, F., \& Redoano, M. (2015). Intergovernmental grants as signals and the alignment effect: Theory and evidence. Journal of Public Economics, 123, 78-91. Recuperado de https:// doi.org/10.1016/j.jpubeco.2014.11.007

Brollo, F., \& Nannicini, T. (2012). Tying Your Enemy's Hands in Close Races: The Politics of Federal Transfers in Brazil. American Political Science Review, 106(4), 742-761. Recuperado de https://doi. org/10.1017/S0003055412000433

Cruz, T., \& Silva, T. (2020). Minimum Spending in Education and the Flypaper Effect. Economics of Education Review, 77, 102012. Recuperado de https://doi.org/10.1016/j.econedurev.2020.102012

De Renzio, P., Wehner, J., \& Wehner, J. (2017). The Impacts of Fiscal Openness (SSRN Scholarly Paper ID 2602439). Rochester, NY: Social Science Research Network. Recuperado de https://papers.ssrn.com/ abstract $=2602439$
Decreto $n^{\circ}$ 10.046, de 9 de outubro de 2019. (2019). Recuperado de http://www.planalto.gov.br/ ccivil_03/_Ato2019-2022/2019/Decreto/D10046. htm

Feld, L. P., \& Schaltegger, C. A. (2005). Voters AS A Hard Budget Constraint: On the Determination of Intergovernmental Grants. Public Choice, 123(1-2), 147-169. Recuperado de https://doi.org/10.1007/ s11127-005-0265-1

Fraga, F. V. (2016). O Descumprimento dos Requisitos Fiscais do CAUC e o Financiamento Municipal: Uma Análise sobre a Burocratização do Serviço e o Princípio da Eficiência (Dissertação de Mestrado). Universidade Católica do Salvador, Salvador, BA.

Graça, L. F. G. (2016). O governo do estado e a assembleia legislativa: entre a submissão e os limites da independência. Curitiba, PR; Belo Horizonte, MG: Appris Editora; Livraria Eireli.

Hellevik, O. (2009). Linear versus logistic regression when the dependent variable is a dichotomy. Quality \&Quantity, 43(1), 59-74. Recuperado de https://doi. org/10.1007/s11135-007-9077-3

Lei Complementar no 64, de 18 maio 1990. (1990). Estabelece, de acordo com o art. $14, \$ 9^{\circ} \mathrm{da}$ Constituição Federal, casos de inelegibilidade, prazos de cessação, e determina outras providências. Brasília, DF. Recuperado de http://www.planalto.gov. br/ccivil_03/leis/lcp/Lcp64.htm

Lei Complementar $n^{\circ} 101$, de 4 de maio de 2000. (2000). Estabelece normas de finanças públicas voltadas para a responsabilidade na gestão fiscal e dá outras providências. Brasília, DF. Recuperado de http://www.planalto.gov.br/ccivil_03/leis/lcp/ lcp101.htm

Lei Complementar $n^{\circ}$ 135, de 4 de junho de 2010. (2010). Altera a Lei Complementar no 64, de 18 de maio de 1990, que estabelece, de acordo com o $\$ 90$ do art. 14 da Constituição Federal, casos de inelegibilidade, prazos de cessação e determina outras providências, para incluir hipóteses de inelegibilidade que visam a proteger a probidade administrativa e a moralidade no exercício do mandato. Brasília, DF. Recuperado de http://www. planalto.gov.br/ccivil_03/leis/lcp/Lcp135.htm

Lei $n^{\circ}$ 12.527, de 18 de novembro de 2011. (2011). Regula o acesso a informações previsto no inciso 
XXXIII do art. $5^{\circ}$, no inciso II do $\$ 3^{\circ}$ do art. 37 e no $\$ 2^{\circ}$ do art. 216 da Constituição Federal; altera a Lei no 8.112, de 11 de dezembro de 1990; revoga a Lei ${ }^{\circ} 11.111$, de 5 de maio de 2005, e dispositivos da Lei $n^{\circ} 8.159$, de 8 de janeiro de 1991; e dá outras providências. Brasília, DF. Recuperado de http:// www.planalto.gov.br/ccivil_03/_ato2011-2014/2011/ lei/112527.htm

Lima, I. A. (2017). Técnicas Qualitativas em análises de Causalidade: Aplicações do Process Tracing. Revista Eletrônica de Ciência Política, 8(1), 128143. Recuperado de https://doi.org/10.5380/recp. v8i1.50210

Lopes, J. E. G., Filho, J. F. R., Pederneiras, M. M. M., \& Silva, F. D. C. (2009). Requisitos para Aprovação de Prestações de Contas de Municípios: Aplicação de Análise Discriminante (AD) a partir de Julgamentos do Controle Externo. Contabilidade Vista \& Revista, 19(4), 59-83. Recuperado de http://revistas.face. ufmg.br/index.php/contabilidadevistaerevista/ article/view/368

Massiani, J., \& Picco, G. (2013). The Opportunity Cost of Public Funds: Concepts and Issues. Public Budgeting \& Finance, 33(3), 96-114. Recuperado de https://doi.org/10.1111/j.1540-5850.2013.12016.x

Meireles, F. (2019). Alinhamento partidário e demanda por transferências federais no Brasil. Revista de Administração Pública, 53(1), 173-194. Recuperado de https://doi.org/10.1590/0034761220170282

Michener, G. (2019). Gauging the Impact of Transparency Policies. Public Administration Review, 79(1), 136-139. Recuperado de https://doi. org/10.1111/puar.13011

Michener, G., Contreras, E., \& Niskier, I. (2018). Da opacidade à transparência? Avaliando a Lei de Acesso à Informação no Brasil cinco anos depois. Revista de Administração Pública, 52(4), 610-629.

Moutinho, J. A. (2016). Transferências voluntárias da União para municípios brasileiros: Mapeamento do cenário nacional. Revista de Administração Pública, 50(1), 151-166. Recuperado de https://doi. org/10.1590/0034-7612139003

O’Donnell, G. (1998). Accountability horizontal e novas poliarquias. Lua Nova: Revista de Cultura e Política, 44, 27-54. Recuperado de https://doi. org/10.1590/S0102-64451998000200003
Pinho, J. A. G., \& Sacramento, A. R. S. (2009). Accountability: Já podemos traduzi-la para o português?. Revista de Administração Pública, 43(6), 1343-1368. Recuperado de https://doi.org/10.1590/ S0034-76122009000600006

Portaria/MEC no 844, de 8 de julho de 2008. (2008). Define os objetivos do Sistema de Informações sobre Orçamentos Públicos em Educação (SIOPE) e aprova o manual de Instruções para o Usuário do SIOPE. Brasília, DF. Recuperado de https:// www.fnde.gov.br/index.php/acesso-a-informacao/ institucional/legislacao/item/4024-portaria-mecn\%C2\%BA-844,-de-8-de-julho-de-2008

Prado, S. (2001). Transferências Fiscais e Financiamento Municipal no Brasil: Projeto Descentralização Fiscal e Cooperação Financeira Intergovernamental (Relatório de Pesquisa). Rio de Janeiro, RJ: Fundação Konrad Adenauer.

Rocha, A. C. (2013). A realização da accountability em pareceres prévios do Tribunal de Contas de Santa Catarina. Revista de Administração Pública, 47(4), 901-926. Recuperado de https://doi.org/10.1590/ S0034-76122013000400005

Sakurai, S. N. (2013). Efeitos Assimétricos das Transferências Governamentais sobre os Gastos Públicos Locais: Evidências em Painel para os Municípios Brasileiros. Pesquisa e Planejamento Econômico, 43(2), 309-332.

Santana, J. J. B., Jr., Libonati, J. J., Vasconcelos, M. T. C., \& Slomski, V. (2009, dezembro). Transparência fiscal eletrônica: uma análise dos níveis de transparência apresentados nos sites dos poderes e órgãos dos Estados e do Distrito Federal do Brasil. Revista de Educação e Pesquisa em Contabilidade, 3(3), 62-84. Recuperado de https://doi.org/10.17524/repec. v3i3.101

Santos, R. R. dos, \& Rover, S. (2019). Influência da governança pública na eficiência da alocação dos recursos públicos. Revista de Administração Pública, 53(4), 732-752. Recuperado de http:// bibliotecadigital.fgv.br/ojs/index.php/rap/article/ view/79919

Silva, M. S. (2015). Teoria do federalismo fiscal: notas sobre as contribuições de Oates, Musgrave, Shah e Ter-Minassian. Nova Economia, 15(1), 117-137. Recuperado de http://www.redalyc.org/resumen. oa? id=400437538005 
Sistema de Informações sobre Orçamentos Públicos em Educação. (2019). Portal do FNDE. Recuperado de http://www.fnde.gov.br/fnde_sistemas/siope

Soares, M. M., \& Melo, B. G. (2016). Condicionantes políticos e técnicos das transferências voluntárias da União aos municípios brasileiros. Revista de Administração Pública, 50(4), 539-561. Recuperado de http://bibliotecadigital.fgv.br/ojs/index.php/rap/ article/view/63583

Speck, B. (2011). Auditing Institutions. In T. J. Power, \& M. M. Taylor (Eds.), Corruption and Democracy in Brazil: The Struggle for Accountability. South Bend, Indiana: University of Notre Dame Press. Recuperado de https://www.bookdepository. com/Corruption-Democracy-Brazil-Timothy-JPower/9780268038946
Supremo Tribunal Federal. (2020, agosto 24). STF declara inconstitucional norma de SP sobre inclusão de gastos previdenciários nas despesas com educação. Recuperado de http://portal.stf.jus.br/noticias/ verNoticiaDetalhe.asp?idConteudo $=450203$

Veiga, L. G., \& Pinho, M. M. (2007). The political economy of intergovernmental grants: Evidence from a maturing democracy. Public Choice, 133(34), 457-477. Recuperado de https://doi.org/10.1007/ s11127-007-9208-3

Yang, T.-M., \& Maxwell, T. A. (2011). Informationsharing in public organizations: A literature review of interpersonal, intra-organizational and inter-organizational success factors. Government Information Quarterly, 28(2), 164-175. Recuperado de https://doi.org/10.1016/j.giq.2010.06.008

\section{Tássia Cruz}

https://orcid.org/0000-0003-1627-9467

Doutora em Economia da Educação pela Universidade de Stanford; Professora assistente da Escola de Políticas Públicas e Governo da Fundação Getulio Vargas (FGV EPPG). E-mail: tassia.cruz@fgv.br

\section{Gregory Michener}

https://orcid.org/0000-0002-6648-8649

Doutor em Política Comparada e Relações Internacionais pela Universidade do Texas, Austin (EUA); Professor associado da Escola Brasileira de Administração Pública e de Empresas da Fundação Getulio Vargas (FGV EBAPE).E-mail: gregory.michener@fgv.br

\section{Bernardo Andretti}

https://orcid.org/0000-0002-9308-8675

Doutorando em Administração pela Escola Brasileira de Administração Pública e de Empresas da Fundação Getulio Vargas (FGV EBAPE) e mestre pela mesma escola. E-mail: bernardoandretti13@gmail.com 